\title{
EVE'S DAUGHTER, MARY'S CHILD: WOMEN'S REPRESENTATION IN HAWTHORNE'S 'THE BIRTHMARK'
}

\author{
Kary Meyers Skredsvig
}

\begin{abstract}
RESUMEN
El siguiente análisis examina las íntimas relaciones que existen entre la subjetividad, el conocimiento y la representación de las identidades genéricas. En 'La marca de nacimiento', cuento de Hawthorne, Georgiana no solo encarna sino que también internaliza las representaciones patriarcales de la mujer, negando su propio ser.
\end{abstract}

\begin{abstract}
The following analysis examines the intimate, intricate relationships among human subjectivity, knowledge, and representation in terms of gendered identities. In Hawthorne's "The Birthmark," Georgiana not only embodies but internalizes traditional patriarchal representations of women, thus negating selfhood.
\end{abstract}

Anaïs Nin once made the following characteristically astute statement about human nature: "We don't see things as they are, we see them as we are." Although this affirmation might initially appear to render testimony to humans' capacity for self-deception, or perhaps a penchant for denial, closer examination suggests an even more significant aspect of human nature, which is no less real for being intangible: the fact that we are inevitably and inextricably bound to our perceptions, which in turn evolve from and depend upon our sense of self. In other words, "reality" is a construction, not a given; subjective, not objective; dynamic, not fixed. Whatever its conception, it is very closely aligned with human subjectivity at both personal and collective levels. In Nathaniel Hawthorne's short story "The Birthmark," which was originally published in 1843, the ways in which human perceptions of reality are both preordained by the cultural context and tempered by the inidividual appears to be peripheral to the larger, obvious conflict between humanism and science; however, they are really at the very heart of it.

The issues surrounding the concept of human subjectivity are as complex and diverse as those who contemplate them, but for the purposes of this discussion, human subjectivity will be understood as essentially refering to our sense of identity. This identity is in itself fundamentally a perception; our sense of self is a combination of the personal-our private apprehension of who and how we are, the social-our understanding and assimilation of others' views, and the cultural - the inculcation of a variety of collective components which constitute our identity as a member of a larger group. These categories obviously include a series of constitutive elements which interact continuously and significantly, such as age, ethnicity, 
gender, language, education, and experience, which exponentially enhance individual possibilities. The focus of this discussion is the gender factor and its crucial significance in identity issues: how is one's sense of self constituted; to what extent is biology (nature) a factor in determining one's mentality, temperament, and behavior; to what extent is cultural conditioning a determinant in the aforementioned areas; what are the repercussions of gendered identities. In "The Birthmark," these concerns are not only the basis for character development of all three characters, but also the prime component of plot and the harbingers of theme; at issue are gendered politics and the juxtaposition of gendered identities.

Traditionally, patriarchal discussions of the human condition have followed the pattern of assuming that male concerns, perceptions, and assumptions are somehow universal, as clearly seen, for example, in the choice of "Man" as a synonym for humankind. As suggested above, traditional criticism of Hawthorne's story has centered on a perceived polarization of humanism and science, which responds to traditional patriarchal concerns with "man's place" in the universal scheme of things. Quite literally, this place has been occupied by males only, with women being significant only to the extent that they affect the men around them. Recognition of this fact and commitment to changing this patriarchal reality has been a cornerstone of the feminist movement since its onset-considered by some to be more of an onslaught - in the 1960s. Even before then, of course, many women (and a few men) were aware of and unhappy about the "sexual politics," to borrow Kate Millett's phrase, which ordained that men were by nature superior and a woman's place was necessarily subordinate to them. In 1970 Millett asserted "What goes largely unexamined, often even unacknowledged ... in our social order, is the birthright priority whereby males rule females ... [despite the fact that] sexual dominion [is] the most pervasive ideology of our culture and provides its most fundamental concept of power" (25). Sherry Ortner enlarges the discussion by identifying three basic dimensions of gender hegemonies: prestige and social status, male domination vs. female subordination, and female power (140), which although differentiated are closely intertwined. Ortner suggests that these are related to issues of cultural and personal space, nature/culture debates, agency/subjectivity, and, of course, sociopolitical structures and functions.

Writing decades earlier, Simone de Beauvoir shares many of their concerns and questions, as well as conclusions. In The Second Sex, Beauvoir argues that men have appropriated the "center," with women's collusion: "She is defined and differentiated with reference to man and not he with reference to her ... He is the Subject, he is the Absolute-she is the Other" (xxii). Of great importance here is not only the hegemony, but also the establishment of identities. Beauvoir suggests that differentiation with an "other" is one means of self-definition, and she provides a wealth of illustrations and examples to explain women's significance as "Other" to men. She begins by differentiating two types of alterity, one in which a reciprocity exists which confers a degree of equality as subjects, and another in which there is no direct, autonomous relationship and therefore no true duality. In the case of male/female relationships, Beauvoir asserts that women have always been regarded as "the absolute Other," as the inessential, and therefore have been subordinated as inferior, a situation which is "validated" historically in patriarchal arguments in which "the dominant class bases its argument on a state of affairs that it has itself created" (xxx) and then tautologically presents as evidence of "absolute truth." Beauvoir provides many different patriarchal definitions of female "otherness," from "flesh" to "nature" to "mediatrix" to "mystery," concluding that each patriarchal society and each male individual establishes its/his own self-image first, then assigns a correlative meaning 
to the female "other." Most significantly, in every case women's identity and significance are decided by another, never self-defined.

Female "otherness" thus takes on a variety of characteristics and roles to serve patriarchal needs and purposes, and they are generally perceived in terms of masculine/feminine polarities which are omnipresent in patriarchal patterns and norms to the present. Following the lead of Aristotle, who defined the male role in reproduction as that of providing the form or essence, while women merely supply the material, patriarchal dichotomies have tended to associate men with everything intellectual and abstract-ideas, ideals, truth, law-while women have been ascribed the emotional and physical-feelings, nurturing, caretaking, the practical. As Mary Ellmann has examined so effectively in Thinking About Women, male/female differences have come to be polarized as not only the abstract vs. materiality, but also art vs. artifice. Men are perceived as those capable of all that is lofty, imaginative, creative, and original, while women are relegated to "lower" (this valuation is in itself a construct, of course) realms of reproduction, imitation, supplementation, and maintenance.

A very significant outgrowth of this type of Manichean polarization is the dichotomous association of men with culture and women with nature. As Sherry Ortner describes it, culture is "broadly equated[d] with the notion of human consciousness, or with the products of human consciousness (i.e., systems of thought and technology) by means of which humanity attempts to assert control over nature" while nature is used as a label for "that which is nonhuman" and that which is most disturbingly human, that is, the inevitability of the life cycle (25-6). Ortner asserts that nature is universally devalued as a "lower order of existence" than culture and that all culture is "engaged in the process of generating and sustaining systems of meaningful forms by means of which humanity transcends the givens of natural existence, bends them to its purposes, controls them in its interest" (25). Moreover, "[s]ince it is always culture's project to subsume and transcend nature, ... then culture would find it 'natural' to subordinate, not to say oppress, [women]" (27). As Beauvoir sees it, this not only explains the cultural mythology which serves as the foundation of all patriarchal societies, but also provokes a fundamental ambivalence in men's attitudes and behavior towards women: "man desires to possess . . . that which he is not, he seeks union with what appears to be Other than himself," at the same time that he rejects and frees himself from nature when he "escapes her hold" (74-75).

According to Beauvoir, it is this curiously paradoxical relationship of men with women/nature, one in which men are both inescapably bound to nature but wish to transcend it, that explains "why woman incarnates no stable concept": "through her is made unceasingly the passage from hope to frustration, from hate to love, from good to evil, from evil to good" (144). Millett also sees this ambivalence as closely related to men's "fear of otherness" (46) and rationalization of women's "inferiority." In literature, as has been amply analyzed and documented by at least two generations of feminist critics and theorists, this ambivalence has been translated into two traditional, contradictory, female representations, commonly identified as the angel, or idealized woman, and the demon, or villified woman. Drawing upon the Christian heritage of western societies, these categories are often seen as derivatives of the Bible's most famous females: Eve, Adam's companion, and Mary, the mother of Jesus.

Both women are defined in terms of the men in their lives, thus identifying them as essentially "other": Eve is described as quite literally having been formed from Adam's rib as 
an afterthought, a means for providing companionship, while Mary is little more than a willing vessel through which the Holy Spirit can incarnate God's will. Eve, a descendent of the Pandora of classical mythology, is canonized as the very spirit of disobedience and credited with no less than the fall from grace of all humanity; because she succumbed to temptation, and worse yet, persuded Adam to follow her terrible example, all humans are punished with lives of hardship. Mary, on the other hand, is presented as the pinnacle of virtue: unquestioning, submissive, obedient, gentle, pure (so pure that no sexuality taints her motherhood). Descendants of Eve include all those women who manifest characteristics of seduction, temptation, disobedience, rebelliousness, autonomy, and carnality (all of which are frequently associated with beauty), while Mary's metophorical daughters are those who maintain their innocence, virtue, purity, gentility, nurturing, subservience, docility, and silence. It is important to emphasize that the above traits are perceived as being inherited exclusively by their female "children," perhaps again following Aristotle's lead in ascribing all that is most negative to women and all that is most positive to men. Mary's "attributes" are perceived as positive from a patriarchal perspective only as desirable qualities in women, never in men, and Eve's intellectual curiosity, proclivity for action, and initiative are lauded only in men, never in women.

Whether as saints or sinners, traditional literary representations of women have been remarkably consistent; Hawthorne's innovation in "The Birthmark" consists of combining them into a single character, Georgiana. According to David Reynolds' analysis of Hawthorne's place within the cultural and literary contexts of his time, this is characteristic of Hawthorne's female protagonists during the time period in which "The Birthmark" was published. Although Reynolds does not discuss this particular short story, he asserts that the heroines of Hawthorne's early stories (1828-1837) are characterized by their heterogeneity and those of the middle period by "fusions" of different qualities, while in his later works there is a "fairly straightforward division between a 'light' . . .and a 'dark' heroine" (375).

Reynolds elaborates rather extensively on the ways in which these female characters are representative not only of literary trends of the nineteenth century U.S., but also of cultural patterns and norms of the time. Reynolds' version of the "saint," the "moral exemplar" tended to be represented as one of two types: the "angelic" or "gentle" variety was rarely gender-specific and basically "replaced" the formerly sacrosanct male moral-authority figures (especially clergy) as a "benign version of God's relation with humanity," while the "practical woman" embodied a "tougher alternative to America's powerful orthodox religious tradition" by the way in which she "flew in the face of Calvinistic gloom, and her persevering good works put the lie to Calvinistic predestination" (342-3). Reynolds' sinner, the "female rogue" also has a variety of guises, from the "female criminal" to the "fallen woman" to the "sensual woman," not to be confused with the "adventure feminist" of the frontier novels or the "female victim" of social reform texts. According to Reynolds, the woman-as-moral-model responds to "conventional" sentimental-domestic fiction which attempted to "avoid or defeat [social] ambiguities," while the other evolved from "subversive" sensational and/or "radical/democrat" writing which allowed these ambiguities to erupt (9). It goes without saying that Reynolds, while careful not to slight the literary genesis and repercussions of "major" authors of the American Renaissance, finds it necessary to examine their works from a cultural perspective in which Hawthorne emerges as himself "representative" of the multiple social realities of the time. 
"The Birthmark" clearly revolves around a major concern of mid-nineteenth century U.S. society, the role of science in humans' lives, but in so doing it manifests crucial issues of gender identity and roles at personal and social levels. There is even a significant question in terms of which character should be considered the protagonist. From a patriarchal perspective, Aylmer is the protagonist, and the conflict is between science and humanism, or to put it another way, between mind and matter. From a feminist perspective, Georgiana is the protagonist, and the conflict is between autonomy and submission. The ways in which Aylmer, Aminadab, and Georgiana are represented reveal an overlapping of gender, moral, and philosophical issues in this story.

Aylmer is not only introduced in the loftiest of terms, but is consistently associated throughout the story with the highest of intentions, standards, and worth. The narrator initiates this deification by identifying Aylmer foremost, in the very first sentence, as "a man of science -an eminent proficient in every branch of natural philosophy" (2147). It is not insignificant that "natural philosophy" is used as a synonym for "science," given the traditional status accorded to philosophy. In this context, "natural" does not suggest anything innate or instinctual, of course, but rather is used as an adjective for what today would be called physical sciences. The word "science" itself was (and is) a term associated with critical thinking, analysis, abstraction (even if "applied"), and objectivity. According to the narrator, the incredible potential of science was just beginning to be perceived: "In those days, when the comparatively recent discovery of electricity, and other kindred mysteries of nature, seemed to open paths into the region of miracle ..." (2147). So powerful was this realm of science that it appeared to have no limit: "The higher intellect, the imagination, the spirit, and even the heart, might all find their congenial aliment in pursuits which . . . would ascend from one steop of powerful intelligence to another, until the philosopher should lay his hand on the secret of creative force, and perhaps make new worlds for himself" (2147).

Perhaps because science as a field of inquiry was perceived as still so new, it was mixed with feelings and desires, for the narrator affirms that Aylmer's love for his new wife could only become strong by "intertwining itself with his love of science, and uniting the strength of the latter to its own." More importantly, the narrator speculates whether or not Aylmer "possessed this degree of faith in man's ultimate control over nature." The choice of the word "faith" is an interesting concession to possible limitations or inadequacies, but there is no such hesitancy in stating the ultimate goal or agency. "Man" is the only being capable of such achieving such aspirations, which more than aspirations, are presented as a necessity; clearly, it is man's "higher intellect" which permits him to vanquish, an intelligence beyond the realm of possibility for women, once again dating back philosophically to Aristotle's conviction that only men (and in particular, masters) had the capacity for and access to truth, while women were unable to surpass "opinion." Georgiana herself describes her own level of comprehension as "simple," and the narrator concurs by describing her understanding of the marvelous optical phenomena with which her husband amused her as merely "some indistinct idea."

Aylmer's professional, psychological, and physical features are all construed as manifestations of his superior nature. In classic physiognymic fashion, his insubstantial physical features are seen to represent illusive "higher" qualities of the human condition: "Aylmer's slender figure, and pale, intellectual face, were . . . apt[ly] a type of the spiritual element" (2151). He was not only confident, but arrogant about his professional abilities: he was "confident in his science" to the point where he felt sure "he could draw a magic circle round 
[Georgiana], within which no evil might intrude" (2151). He declares, "I feel myself fully competent to render this dear cheek as faultless as its fellow; and then . . . what will be my triumph, when I shall have corrected what Nature left imperfect, in her fairest work!" (2150). His fame is as extensive as his ambition: his scientific successes began while he was "yet in his youth," when "he had made discoveries in the elemental powers of nature, that had roused the admiration of all the learned societies in Europe" (2150). In short, Aylmer had had an "ardent, ambitious, imaginative, yet practical and laborious, life" during which he had "redeemed himself from materialism, by his strong and eager aspiration towards the infinite" (2154). His ambition has no limits; he even aspires to producing the very Elixir of Immortality and Elixir Vitae--goals which he believed possible "by the plainest scientific logic," even though he believes that "a philosopher who should go deep enough to acquire the power, would attain too lofty a wisdom to stoop to the exercise of it" (2152). Once again, materiality is subordinated to intellect, and Aylmer is the exclusive representative of "mind and spirit" in this story.

Georgiana's attitudes and feelings toward Aylmer's scientific abilities essentially reinforce his self-image and public image, although, like the narrator's, they are not unequivocal. On the basis of his reputation, she beseeches him to remove her birthmark: "You have deep science! All the world bears witness of it. You have achieved great wonders" (2149). However, when she reads his folio of scientific experiments, she is forced to modify her perception of him somewhat: "Georgiana, as she read, reverenced Aylmer, and loved him more profoundly than ever, but with a less entire dependence on his judgment than heretofore. Much as he had accomplished, she could not but observe that his most splendid successes were almost invariably failures, if compared with the ideal at which he aimed" (2154). The male intellectual circle emphasizes what is written, the theory, while Georgiana is concerned about practical results. Nevertheless, she claims that her reading has made her "worship [Aylmer] more than ever," an attitude of which he entirely approves: "Ah! wait for this one success, ... then worship me if you will. I shall deem myself hardly unworthy of it" (2154).

So great is her respect for and awe of Aylmer, however, that Georgiana affirms - even as she is dying-that he has "aimed loftily" and "done nobly" and "should not repent" of "so high and pure a feeling" (2157). This is either amazingly delusional or unbelievably masochistic, considering that Georgiana "well knew" that even should the experiment be successful, she could "satisfy his highest and deepest conception" only momentarily because "his spirit was ever on the march-ever ascending - and each instant required soething that was beyond the scope of the instant before" (2156). Georgiana not only recognizes but also supports Aylmer's desire to surpass human limits; she "joyfully stake[s] all upon [his] word", as she herself acknowledges, "on the same principle that would induce me to take a dose of poison, if offered by [Aylmer's] hand" (2155). Perhaps Georgiana's unwillingness to diminish Aylmer's reputation and her eagerness to maintain his monumental ego are somehow related to comments by the narrator to the effect that, no matter how godlike his scientific knowledge and talents might be, Aylmer is merely mortal, after all. Georgiana pragmatically accepts human limitations, while Aylmer either denies or fights against them.

Georgiana and the narrator seem to concur that Aylmer's volume of experiments, "rich with achievements that had won renown for its author, was yet as melancholy a record as ever mortal hand had penned": "It was the sad confession, and continual exemplification, of the 
short-comings of the composite man - the spirit burthened with clay and working in matterand of the despair that assails the higher nature, at finding itself so miserably thwarted by the earthly part" (2154). In other words, Aylmer, as a living human being, cannot escape the limitations of his physical nature, no matter how longingly he aspires to "the completeness of a higher state" (2157). The narrator is quite sympathetic in blaming human nature rather than individuals, observing that the tomes of the philosophers of the middle ages (all men, naturally) "stood in advance of their centuries, yet were imbued with some of their credulity, and therefore were believed, and perhaps imagined themselves, to have acquired from the investigation of nature a power above, nature, and from physics a sway over the spiritual world" (2153-4). The choice of the verbs "believe" and "imagine" suggests that these masculine aspirations are doomed to failure, more a figment of wishful thinking than a portent of future success.

This is reinforced in the character of Aylmer when he literally dreams of eliminating Georgiana's birthmark, fully unaware how accurate his subconscious drama would prove to be. Ironically, his dream is more "realistic" than his science. The visual illusions he creates for her are "almost perfect enough to warrant the belief, that her husband possessed sway over the spiritual world"; conversely, this dream, which appears to be mere imagination, proves to be an unheeded forewarning of imminent failure. The narrator also subtly undercuts Aylmer's pretensions by commenting that the early volumes of the Transactions of the Royal Society, "in which the members, knowing little of the limits of natural possibility, were continually recording wonders, or proposing methods whereby wonders might be wrought" in ways which were "hardly less curious and imaginative" than those of earlier tomes. The fact that the discussion of Aylmer's personal folio follows these observations tends to reveal it as merely the latest in a long, historical progression of failed attempts to surpass human limits.

Aminadab serves as a sort of alterego for Aylmer, embodying that "gross Fatality of Earth" (2157) which is the counterpart to Aylmer's intellectual and spiritual nature. Aminadab is described as "a man of low stature, but bulky frame, with shaggy hair hanging about his visage," a creature of "vast strength . . . and indescribably earthiness" who "seemed to represent man's physical nature" (2150-1). His "harsh, uncouth, misshapen tones" were "more like the grunt or growl of a brute than human speech" (2152). He had been Aylmer's assistant for his entire professional life, and "was admirably fitted for that office by his great mechanical readiness." Unlike Aylmer, however, this earthly version was "incapable of comprehending a single principle," although he "executed all the practical details of his master's experiments" (2151); as a representative of mere matter, he can acquire manual skills but not intellectual ones. Like the traditional representation of women as nature, he can reproduce, but not create on his own; he is totally dependent upon Aylmer's higher nature to provide the ideas, the essence, while his contribution is purely physical. The ways in which Aylmer addresses Aminadab clearly reinforce their opposition and the fact that Aminadab is only body: "thou human machine", "thou man of clay", "clod", "earthly mass", "thing of senses." Moreover, in a rare moment of appreciation, he affirms that Aminadab has "served him well! Matter and Spirit_Earth and Heaven-have both done their part in this!" (2157), acknowledging the participation of that specimen of lower nature, if not granting it equality.

Aminadab's setting is also appropriate to his nature and to his function. As a representative of physicality, it is "natural" that he should be found in the basement chambers, in the grimy bowels of the laboratory, illuminated by the primal fires of the furnace. If the physical 
dimension of human nature is considered "inferior", "lower", "gross", "fatal", it makes sense to banish it to the netherlands of the cavelike part of the laboratory. For the same reasons, it makes sense to establish Georgiana's quarters there as well. But although these two people both represent human physicality, there is one important difference: Aminadab, as a male-no matter how "primitive"-has privileges that Georgiana will never have. He is allowed to participate actively in Aylmer's science, while Georgiana's participation can only be passive. Georgiana's quarters are decorated with beautiful curtains, scents, and other amenities, which both the narrator and Aylmer present as an attempt to make her sojourn there as pleasant as possible; however, the real objective is to strictly limit her personal space within the laboratory. For all practical purposes, Georgiana is a prisoner in her quarters, which is why her first entrance into the laboratory is described as an "intrusion" and her husband's initial reaction is to accuse her of risking the success of his scientific ventures by "throw[ing] a blight . . . over [his] labors" (2155). Quite clearly, each person has his/her "proper" place, and it is Aylmer who decides what that is.

Feminist critics, notably Sandra Gilbert and Susan Gubar, have frequently noted a literary penchant for female confinement which parallels the restrictions on women's real lives. In The Madwoman in the Attic, Gilbert and Gubar demonstrate how, for example, in Victorian fiction, a favorite strategy was literally to lock "mad" (rebellious?) women in the attic, a very graphic symbol of enclosure. Metaphors of enclosure and confinement abound in relation to literary women: houses and rooms are commonly used as symbolic spaces. Gilbert and Gubar (ironically) agree with Freud that a cave is "a female place, a womb-shaped enclosure, a house of earth, secret and often sacred." Perhaps the primary metaphor for "containment," however, is patriarchal insistence on restricting women to their own bodies, a clearly defined, "appropriately" limited space. In Gender/Body/Knowledge, Susan Bordo, among others, reminds us that "the body is not only a text of culture [but] also a practical, direct locus of social control" (13). Bordo differentiates between the "useful" body, a register of the cultural body following Foucault's ideas, and the "intelligible" body, our cultural conceptions of the body, which may be complementary or contradictory. As a female, Georgiana is a potential threat who is best incapacitated by "enclosing" her in a "safe" place. A significant step towards dominating nature is to attempt to bind it, to limit its realm.

The symbol of Georgiana's physicality is, of course, her birthmark. It is "a singular mark, deeply interwoven ... with the texture and substance of her face", and its shape "bore not a little similarity to the human hand" (2147-8). Its hue varies from the "deeper crimson" in the "healthy, though delicate bloom" of her usual complexion, to becoming nearly imperceptible in the midst of blush, to "a crimson stain upon the snow" when she turned pale. Reactions to it varied, also: some women called it the "Bloody Hand" and saw it as a hideous detraction to her beauty, while male admirers speculated that it was the handprint of a fairy at the hour of birth, "in token of the magic endowments that were to give her such sway over all hearts" (2148). This male association of the birthmark with magic is in keeping with patriarchal tradition associating women with all that is mysterious, changeable, unintelligible, intangible, intuitive, or inexplicable. Other male observers simply wished it were not there to keep Georgiana from "ideal loveliness." It is not insignificant that her birthmark is compared to "one of those small blue stains, which sometimes occur in the purest statuary marble" and which could debatably "convert the Eve of Powers to a monster." At its most negative, this 
birthmark is what transforms Georgiana from the embodiment of an ideal into the personification of "the fatal flaw of humanity": "The Crimson Hand expressed the ineludible gripe [sic], in which mortality clutches the highest and purest of earthly mould, degrading them into kindred with the lowest, and even with the very brutes" (2148). In other words, Georgiana's birthmark is visible confirmation not only of human mortality but of human inferiority, which is represented as female.

Aylmer perceives Georgiana's birthmark as "the symbol of his wife's liability to sin, sorrow, decay, and death" (2148), and thus understandably becomes obsessed with removing it. Interestingly, the birthmark did not seem to bother him until Georgiana became his wife; it is only when she "belongs" to him that he sees her physicality as a reflection on himself, and quickly finds the mark unbearable. One day "very soon after their marriage," Aylmer expresses his concern: "you came so nearly perfect from the hand of Nature, that this slightest possible defect . . . shocks me, as being the visible mark of earthly imperfection" (2147). Aylmer despises this reminder of his own mortality, at the same time that he aspires to having "the perfect wife," as befits his status as eminent scientist. Georgiana apparently qualifies well for that position in terms of temperament; she is liked and admired by all who know her (even Aminadab). She also embodies those traits considered desirable in a wife: she is demure, proper, delicate, supportive, refined, and, above all, submissive. Although her initial reaction to Aylmer's statement about her birthmark is anger, her anger is immediately subsumed in tears and very shortly transformed into solidarity with her husband's attitudes and feelings: "lifewhile this hateful mark makes me the object of your horror and disgust-life is a burthen [sic] which I would fling down with joy. Either remove this dreadful Hand, or take my wretched life!" (2149). Georgiana willingly revises her original estimation of the mark as a "charm" and accepts her husband's judgment unquestioningly.

Because the birthmark is so intimately connected to Georgiana, to the point where it serves as a sort of visible barometer of her feelings, it is transformed into something approximating essence. Both Aylmer and Georgiana suspect that "the stain goes as deep as life itself," which is consistent with its having been "laid upon [her] before [she] came into the world" (2149). In other words, this "defect" is both innate and inherited, and its significance becomes one of the very nature of Georgiana. The mark is a manifestation of human imperfection, yes, and because of it Georgiana believes she is "of all mortals the most fit to die" (2156). As much as Aylmer would like to idealize her into a symbol for perfection, the little hand prevents him from doing so successfully. When Georgiana professes her complete faith in his ability and knowledge, he responds by declaring " there is no taint of imperfection on thy spirit" (2156); clearly, spiritual perfection in a woman consists of accepting the superiority of her husband. And as hard as Georgiana tries to be the perfect wife, perfection is simply beyond the realm of the possible because of this physical flaw. The fact that she is even willing to risk death in order to please her husband must surely be recognized as the ultimate sacrifice. However, Aylmer is ironically not the least bit concerned about Georgiana or possible consequences for her; he sees this situation in terms of himself only. The operation is an opportunity for him to correct nature's mistake and to achieve personal glory; tellingly, it is also the only way to "give himself peace." Aylmer's self-absorption is as monumental as his arrogance in believing himself capable of improving over nature and as his capacity for denial in so quickly forgetting his "mortifying failures". 
Georgiana sees her birthmark as a symbol for her self, also, and it is a flawed self which she perceives. She bemoans her inability to achieve not only physical, but also moral perfection: "Life is but a sad possession to those who have attained precisely the degree of moral advancement at which I stand. Were I weaker and blinder, it might be happiness. Were I stronger, it might be endured hopefully" (2156). What is most important in her perception of weakness and imperfection, however, is the way in which she assimilates Aylmer's attitudes of blame: she assumes personal guilt for the flaws of human nature. Aylmer projects the blame for human imperfection upon his wife, and Georgiana willingly accepts the guilt. Essentially she is negating her own intuition and her own capacity for knowing by concurring that Aylmer's knowledge and wisdom are superior to her own. In Women's Ways of Knowing, Mary Belenky and associates examine women's answers to questions concerning what is truth, what is authority, to whom do we listen, and especially how do we know what we know. They affirm that "our basic assumptions about the nature of truth and reality and the origins of knowledge shape the way we see the world and ourselves as participants in it" (3). Georgiana's perspective fits into the epistemological position of "received knowledge", that is, of women who "conceive of themselves as capable of receiving . . . knowledge from the all-knowing external authorities but not capable of creating knowledge on their own" (15). Aylmer, as a man and especially as a scientist, is ascribed the authority of knowledge, while Georgiana sees herself only as a receptacle for his wisdom. In spite of clear indications that she is able to reason, and more importantly, understand and question her husband's work, her acceptance of Aylmer's perception and judgment of her as inferior determines her behavior accordingly. Because she has been ascribed the place and stauts of a lesser "other", Georgiana also perceives herself as such, which explains (but does not justify) her almost casual attitude towards her own survival.

When human knowledge is understood as a construction, the knower is part of the known (Goldberger 5). Knowledge and selfhood are inseparable in the sense that our perceptions of who we are and what we are constitute our vision and version of reality. Eve's daughter, Mary's child. In a patriarchal society, men project their desire to transcend human limitations and neutralize their fear of the other by constructing an idealized version of women, females who inherit Mary's angelic qualities. She is the representation of otherness in its most perfect form: a complementation which enhances and aggrandizes men's self-image with no threatening overtones. But just as otherness is essential for self-definition, so it can never be fully understood and assimilated, at the risk of its disappearing entirely. In a patriarchy, the indomitable aspects of womanhood are projected onto the figure of Eve, who embodies everything which is problematic and negative about otherness. In analyzing "The Birthmark", the thoughtful reader must question why Georgiana is chosen to represent flawed humanity, even though her nature would appear to be "higher" than Aminadab's and her husband is unequivocably revealed to be less than perfect himself. The explanation is quite simple: she is perceived and projected as inferior because she is not a man. It is ironic that while there is little of the personal in this valuation, Georgiana assumes responsibility not only for her own guilt, but also quite literally for all of "mankind." Even more ironically, in so doing she transforms herself from a demonic Eve into a self-sacrificing Mary, thus perpetuating those most sacred of patriarchal myths: women as both the active cause of fallen humanity and the passive vehicle for human redemption. 


\section{Bibliography}

Auerbach, Nina. 1982. Woman and the Demon: The Life of a Victorian Myth. Cambridge: Harvard UP.

Beauvoir, Simone de. 1952. The Second Sex. Trans. H. M. Parshley. NY: Vintage.

Bordo, Susan. 1989. "The Body and the Reproduction of Femininity: A Feminist Appropriation of Foucault." Gender/Body/Knowledge. Eds. Alison M. Jaggar and Susan R. Bordo. New Brunswick: Rutgers. 13-33.

Ellmann, Mary. 1968. Thinking About Women. NY: Harcourt Brace Jovanovich.

Fetterley, Judith. 1978. The Resisting Reader: A Feminist Approach to American Fiction. Bloomington: Indiana UP.

Gilbert, Sandra M. and Susan Gubar. 1979. The Madwoman in the Attic: The Woman Writer and the Nineteenth-Century Literary Imagination. New Haven: Yale UP.

Goldberger, Nancy et al (eds.). 1996. Knowledge, Difference, and Power. NY: Basic/Harper Collins.

Hawthorne, Nathaniel. 1843. "The Birthmark." The Heath Anthology of American Literature. Vol. I. 2nd ed. Eds. Paul Lauter et al. 1994. 2147-2158.

Millett, Kate. 1970. Sexual Politics. NY: Doubleday.

Mitchell, W. J. T. 1995. "Representation." Critical Terms for Literary Study. 2nd ed. Eds. Frank Lentricchia and Thomas McLaughlin. Chicago: U Chicago P. 11-22.

Ortner, Sherry. 1996. Making Gender: The Politics and Erotics of Culture. Boston: Beacon.

Reynolds, David S. 1989. Beneath the American Renaissance: The Subversive Imagination in the Age of Emerson and Melville. Cambridge: Harvard UP. 